\title{
Complementary and Alternative Medicines (CAM) and its Role in Thalassemia Treatment
}

\author{
Wan Ismahanisa ${ }^{1}$, Mohamed Azmi Hassali ${ }^{2}$, Ramli Mohd Yunus ${ }^{3}$ and Maryam Farooqui ${ }^{4 *}$ \\ ${ }^{1}$ Faculty of Health Science, Universiti Teknologi MARA (UITM) Penang, Malaysia \\ ${ }^{2}$ Discipline of Social and Administrative Pharmacy, Universi Sains Malaysia, Penang, Malaysia \\ ${ }^{3}$ Thalassemia International Board Member, Malaysia \\ ${ }^{4}$ Faculty of Pharmacy, Universiti Teknologi MARA (UITM) Penang, Malaysia
}

Predominantly Complementary and Alternative Medicine (CAM) is considered as health care practices that differ from the biomedicine [1]. Worldwide the estimated adult general population for CAM use varies from as low as $32 \%$ [2] to as high as $80 \%$ [3].

CAM use is common among patients with chronic diseases such as arthritis, cancer [4], Acquired Immunodeficiency Syndrome (AIDS) [4]. Thalassemia is a chronic life long illness which requires biomedicine treatment for the first few months after birth and persisted until death. The World Health Organization (WHO) listed the hemoglobinopathies disorder such as thalassemia as one of urgent health problems which has considerable impact on health care system. In addition WHO concerns, because due to high cost of treatment for thalassemia, its increasing prevalence, morbidity, mortality rates within few years of life in people left untreated [5]. The differences in CAM estimates have been attributed to time or place but CAM estimates for apparently similar to the population that take around the same time. For example estimated American children with cancer from 8.7\% [6] to 65\% [7] use $\mathrm{CAM}$ as a treatment. The reason the people with the serious illness use CAM in the situation of highly sophisticated biomedicine has proven that difficult to determine.

Even though CAM treatment can reduce the morbidity and the mortality but it may have potentials of unnecessary interactions with the prescribed biomedicines. For example the CAM therapies such as herbs and vitamin can mask or distort the biomedical treatments and for this reason the possible effect of combining biomedical and CAM might give harmful effects or may lead to inaccurate biochemical results. Such concerns are probable because people with chronic disease have been found always use CAM therapies at the same time with biomedicine.

Thalassemia is a chronic condition that requires regular blood transfusion. Whilst, most research that related to thalassemia was limited to biomedical issues (such people might also use CAM as their treatment. A comprehensive search of the literature review yielded that only one article that specifically related to CAM and thalassemia. This article detailed that the children use of CAM and majority of the parents (36.1\%) stated that they used CAM to ensure their children's health and protect them against disease [8]. Moreover the study of the reasons for CAM used and its disclosure to treating practitioners has never been undertaken with people that who depend on the biomedicine treatment from cradle to grave. Thus the exploration of the reasons of CAM use and disclosure to amongst people with lifelong condition like Thalassemia is deemed necessary. Therefore the most studies that shows the participants that using CAM because to avoid or relief the musculoskeletal problems and distressing and painful conditions [9] which suggest that CAM use was for a treatment not on lifestyle practice. For example poorer physical health associated with chronic illnesses with accounted $60 \%$ of CAM use and $35 \%$ of such use for pain.

It is important to study of thalassemia because there are intensively biomedical treated for the duration of their life, which means the person that use of CAM might be jeopardising their health.
The review of the existing literature on CAM disclosure suggested that CAM disclosure estimates were disproportionate with estimates for CAM use in thalassemia [10] whilst the research into illness like thalassemia is extensive and there is no knowledge to concurrent related to CAM and biochemical use amongst this population. Hence this issue highlight the CAM and the importance on the frequency of use and the reasons why people with thalassemia use CAM despite their lifetime and need of the biomedical treatment.

The enduring nature of chronic illness such thalassemia, places are demands on people who have such illness. It includes the need for them to follow the invasive of the treatment and the medication which can emphasize health's problem. The thalassemia patient is in need of the biomedical treatment from the infant until death and it is most severe form of the haemolytic of the congenital haemolytic anaemia. Hence the thalassemia major can be categorized as a severe and chronic disease, requiring long life treatment. This study is the first to explore the issues that related to the use and disclosure of CAM use and disclosure by the chronically ill by the exploring the discrepancy of the rise of CAM use and the limited of the disclosure to the biomedicine practitioners.

\section{References}

1. Caspi O, Koithan M, Criddle MW (2004) Alternative medicine or "alternative" patients: a qualitative study of patient-oriented decision-making processes with respect to complementary and alternative medicine. Med Decis Making 24: 6479.

2. Verhoef MJ, Russell ML, Love EJ (1994) Alternative medicine use in rural alberta. Can J Public Health 85: 308-309.

3. Bodeker G, Kronenberg F (2002) A public health agenda for traditional complementary and alternative medicine. Am J Public Health 92: 1582-1591.

4. Boon H, Stewart M, Kennard MA, Gray R, Sawka C, et al. (2000) Use of complementary/alternative medicine by breast cancer survivors in Ontario: prevalence and perceptions. J Clin Oncol 18: 2515-2521.

5. Webster BH, Lammi AT (1994) Thalassaemia and other haemoglobinopathies in general practice. Aust Fam Physician 23: 1485-1490.

6. Faw C, Ballentine R, Ballentine L, vanEys J (1977) Unproved cancer remedies: a survey of use in pediatric outpatients. JAMA 238: 1536-1538.

*Corresponding author: Maryam Farooqui, Faculty of Pharmacy, University of Ttechnology MARA, Malaysia, Tel: 06-04-5623561; E-mail: maryamfarooqui.uitm@gmail.com

Received November 30, 2013; Accepted November 30, 2013; Published December 02, 2013

Citation: Ismahanisa W, Hassali MA, Yunus RM, Farooqui M (2013) Complementary and Alternative Medicines (CAM) and its Role in Thalassemia Treatment. Altern Integ Med 3: e111. doi:10.4172/2327-5162.1000e111

Copyright: (c) 2013 Ismahanisa W, et al. This is an open-access article distributed under the terms of the Creative Commons Attribution License, which permits unrestricted use, distribution, and reproduction in any medium, provided the original author and source are credited. 
Citation: Ismahanisa W, Hassali MA, Yunus RM, Farooqui M (2013) Complementary and Alternative Medicines (CAM) and its Role in Thalassemia Treatment. Altern Integ Med 3: e111. doi:10.4172/2327-5162.1000e111

Page 2 of 2

7. Friedman T, Slayton WB, Allen LS, Pollock BH, Dumont-Driscoll M, et al. (1997) Use of complementary therapies for children with cancer. Pediatrics 100: E1.

8. Efe E, Işler A, Sarvan S, Başer H, Yeşilipek A (2013) Complementary and alternative medicine use in children with thalassaemia. J Clin Nurs 22: 760-769.
9. Astin JA (1998) Why patients use alternative medicine: results of a national survey. JAMA 279: 1548-1554.

10. Ahmad WIU, Atkin K (1996) "Race" and community care: an introduction. 'Race' and community care. Buckingham: Open University Press. 